\title{
NUEVAS ARVENSES HOSPEDERAS DE BEGOMOVIRUS COLECTADAS EN CULTIVOS DE TOMATE (SOLANUM LYCOPERSICUM L.) EN CUNDINAMARCA
}

\section{NEW WEEDS HOSTS OF BEGOMOVIRUSES COLLECTED IN TOMATO CROPS (SOLANUM LYCOPERSICUM) IN CUNDINAMARCA}

\author{
1 Juan Carlos Vaca-Vaca \\ 2 Diana Marcela Rivera-Toro \\ 3 Jonathan Morales-Euse \\ ${ }^{4}$ Frenyiline Jara-Tejada \\ ${ }^{5}$ Karina López-López \\ $1^{*}$ Doctor en Ciencias biotecnología de plantas. \\ ${ }^{2 *}$ Estudiante magister en Ciencias biológicas. \\ ${ }^{3 *}$ Estudiante magister en Ciencias agrarias. \\ 4* Magister en Ciencias biológicas. \\ $5^{*}$ Doctora en Ciencias Biotecnología de plantas.

\footnotetext{
1 jcvacavalunal.edu.co

2 dmriverat@unal.edu.co

3 jmoralese@unal.edu.co

${ }^{4}$ fjarat@unal.edu.co
} \\ ${ }^{5} \mathrm{klopezl}$ lunal.edu.co
}

* Grupo IPMA Interacción Planta Microorganismo Ambiente, Facultad de Ciencias Agropecuarias, Universidad Nacional de Colombia sede Palmira.

\section{RESUMEN}

Los begomovirus forman parte del grupo de virus emergentes que afectan cultivos de interés agrícola a nivel mundial. Las arvenses podrían constituirse en hospederos alternos de estos virus y constituir fuentes de inóculo. El objetivo de este trabajo fue detectar begomovirus bipartitas en arvenses recolectadas en cultivos de tomate en Cundinamarca, Colombia. Se recolectaron arvenses con y sin síntomas virales en cultivos de tomate localizados en los municipios

de Pasca y Fusagasugá, Cundinamarca. Se purificó el ADN genómico total de cada arvense y, para evidenciar la presencia de begomovirus, se realizó una reacción en cadena de la polimerasa con oligos específicos para detectar el componente genómico A viral. Se recolectaron 36 arvenses, de las cuales 22 especies fueron identificadas taxonómicamente. Stellaria media (L.) Vill., Veronica persica Poir, Galinsoga ciliata (Raf.) S.F. Blake, Malva sylvestris L. y 
una especie de la familia Asteraceae resultaron positivas para begomovirus. Para las especies Stellaria media (L.) Vill. y Galinsoga ciliata (Raf.) S.F. Blake, constituyen el primer reporte a nivel mundial como hospederos de begomovirus. La especie Veronica persica Poir. se identifica como reservorio de begomovirus por primera vez en América Latina. Finalmente, la especie Malva sylvestris L. y una especie de la familia Asteraceae se reportan por primera vez como hospederos de begomovirus para Colombia. El control efectivo de las arvenses identificadas como hospederos para begomovirus es una estrategia efectiva para disminuir el impacto de esta familia de virus en los cultivos de tomate.

Palabras clave: Asteraceae; Galinsoga ciliata (Raf.) S.F. Blake.; geminivirus; malezas; Malva sylvestris L.; Stellaria media (L.) Vill.; Veronica persica Poir.

\section{ABSTRACT}

Begomoviruses are part of the group of emerging viruses that affect crops of agricultural interest worldwide. Weeds can easily become alternate hosts of these viruses and be a source of inoculum for them. The objective of this work was to detect bipartite begomoviruses present in weeds collected in tomato crop in Cundinamarca, Colombia. Weeds were collected with and without viral symptoms in tomato crops located in the municipalities of Pasca and Fusagasugá, Cundinamarca. The total genomic DNA of each weed was purified and to demonstrate the presence of begomovirus a polymerase chain reaction was performed with specific oligos for detected the genomic component A viral. 36 weeds were collected, of which 22 species were identified taxonomically. Stellaria media (L.) Vill., Veronica persica Poir., Galinsoga ciliate (Raf.) S.F. Blake, Malva sylvestris L. and one species of the family Asteraceae were positive for bipartite begomoviruses. For the species Stellaria media (L.) Vill. and Galinsoga ciliate (Raf.) S.F. Blake, they constitute the first report worldwide as begomovirus hosts. The species Veronica persica Poir. is identified as a reservoir of begomovirus for the first time in Latin America. Finally, the species Malva sylvestris $\mathrm{L}$. and a species of the family Asteraceae are reported for the first time as hosts of begomoviruses for Colombia. Effective control of weeds identified as hosts for begomoviruses is an effective strategy to reduce the impact of this virus family on tomato crops.

Key words: Asteraceae; Galinsoga ciliata(Raf.) S.F. Blake.; geminivirus; Malva sylvestris L.; Stellaria media (L.) Vill.; Veronica persica Poir.; weeds
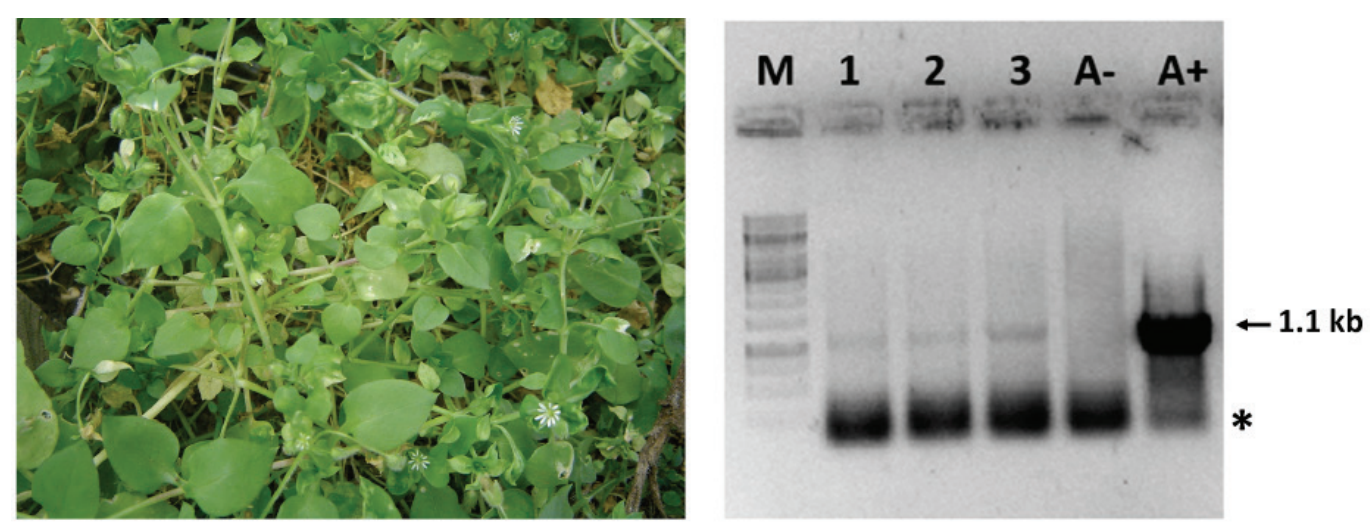

Resumen gráfico. La arvense Stellaria media (L.) Vill. constituye el primer reporte a nivel mundial como hospederos de begomovirus. Detección de begomovirus por PCR. 


\section{INTRODUCCIÓN}

El tomate es la hortaliza más cultivada y de mayor valor económico a nivel mundial (Meza et al., 2013). Bajo ciertas condiciones de humedad y temperatura, este cultivo suele verse afectado por patologías causadas por hongos, bacterias y virus, lo que disminuye la producción y la calidad, teniendo que recurrir a estrategias de control químico, biológico, cultural o genético para poder reducir las pérdidas que estos fitopatógenos puedan ocasionar (Tamayo y Jaramillo, 2013).

En cuanto a las enfermedades virales, la infección por virus en plantas es altamente diversa, la mayoría involucra patosistemas de tres componentes (virus, vector y hospedero), donde cada componente interactúa con el ambiente (Jones, 2014). Los begomovirus (Familia Geminiviridae) se caracterizan por tener uno o dos componentes genómicos de ADN circular de cadena sencilla, denominados ADN-A y ADN-B, cada uno con un tamaño entre $2.5 \mathrm{~kb}$ - 2.6 kb (Zerbini et al., 2017). Los begomovirus son transmitidos por mosca blanca: Bemisia tabaci (Gennadius), de manera circulativa no propagativa, e incluye un grupo de virus que afectan plantas dicotiledóneas de importancia económica (Thompson, 2011).

Latinoamérica tiene la incidencia más alta y diversidad de virus del género Begomovirus en el mundo; por esto, estas regiones sufren las mayores pérdidas en cultivos de importancia económica (Fargette et al., 2006). Estudios previos han demostrado que, en Colombia, los virus pertenecientes a este género presentan un gran potencial patogénico. Por ejemplo, el virus del mosaico amarillo de la papa (Potato Yellow Mosaic Virus - PYMV) que afecta tomate y el virus de la distorsión de la hoja del maracuyá (Passionfruit Leaf Distortion Virus - PLDV) que afecta la maracuyá, ambos pertenecientes a este género y caracterizados en varias investigaciones (Vaca-Vaca, Betancur-Perez y López-López, 2012; Vaca-Vaca, Carrasco-Lozano y López-López, 2018). Estos virus limitan severamente la producción de los cultivos hospederos, lo que comprueba la importancia su estudio para el desarrollo de alternativas efectivas de control.

Las arvenses compiten con el cultivo por espacio, luminosidad, nutrientes, y agua; y además sirven como hospederos alternos de begomovirus y de los vectores biológicos de estos insectos. Además, constituyen fuentes potenciales de inoculo primario de begomovirus $y$ desempeñan un papel importante como hospedero alterno, permitiendo la propagación a otros cultivos de importancia económica, conduciendo a altas pérdidas en la producción (Prajapat, Marwal, y Gaur, 2014).

Los arvenses, en su papel como hospederos alternos, representan la fuente más importante de virus. La diversidad de estas plantas ofrece a los diferentes virus mayores oportunidades para que se disperse de manera generalizada y así como su presencia continua a través del tiempo, sea mayor (Duffus, 1971). La diversidad de malezas como hospederos alternos de begomovirus es alta y esto ha sido demostrado ampliamente por los estudios sobre virus transmitidos por mosca blanca, en los que se han reportado las arvenses Hybanthus attenuatus, Verbena sp., Croton hirtus, Lantana camara, Amaranthus dubius, Rhynchosia minima, Rivina humulis, Desmodium sp., Caesalpinia sp y Plumbago sp., como hospederas alternas de begomovirus (López-López, JaraTejada y Vaca-Vaca, 2014; Vaca-Vaca, Otavo y López-López, 2011). Recientemente, se reportó la presencia de nuevas arvenses hospederas de begomovirus asociadas al cultivo de ají en Valle del Cauca: Sida acuta, Malvastrum sp, Acalypha sp, Parthenium hysterophorus y 
Euphorbia hirta (Vaca-Vaca, Corredor-Saenz, Jara-Tejada, Betancourt-Andrade y Lopez-Lopez 2019).

Lo anterior justifica la importancia de la realización de estudios que permitan tanto la identificación de los diferentes virus que pueden afectar al cultivo de tomate, así como identificar las arvenses asociadas al cultivo de tomate en Cundinamarca que son hospederas de begomovirus, con el fin de conocer su diversidad y aportar información que podría ser de utilidad para su control para evitar así su posible emergencia y posterior transmisión y adaptación a cultivos de importancia agrícola.

\section{MATERIALES Y MÉTODOS}

\section{Recolección de arvenses en campo}

En septiembre del 2014 se recolectaron hojas, flores y brotes de arvenses asociadas a cultivos de tomate bajo invernadero localizados en la finca San Luis (N 04¹9' 444" W07419'898"), la vereda Buenas tardes ( $N$ 0419' 186" - W074²0'361") ubicados en el municipio de Pasca, Cundinamarca y la finca Brisas de Xochimilco (N 04²0' 611" W074²3'495") en el municipio Fusagasugá, Cundinamarca. Estas muestras se mantuvieron en bolsas de papel. Posteriormente, ya en el Laboratorio de Sanidad y Microbiología agrícola de la Universidad Nacional de Colombia de la sede Palmira se almacenaron en tubos Fal$\operatorname{con}^{\circledR}$ con silica con el fin de desecar los tejidos. Se colectaron las arvenses que convivían con el cultivo de tomate o estaban en los alrededores de este, siendo este el principal criterio de selección de las muestras.

\section{Identificación taxonómica}

Las muestras colectadas en campo se identificaron en el herbario "Josep Cuatrecasas
Arumi" de la Universidad Nacional de Colombia sede Palmira por medio de comparación con literatura y empleando material especializado en taxonomía vegetal.

\section{Extracción de ADN total de arvenses}

La extracción del ADN total de las muestras vegetales se realizó mediante Invisorb Spin Plant Mini Kit (Stratec ${ }^{\circledR}$ ), que es un método en el que se emplean columnas que permiten la purificación de ADN de alta calidad y cantidad, sin contaminación de otras moléculas como proteínas y ARN. A continuación, el ADN vegetal total obtenido se almacenó a $-20^{\circ} \mathrm{C}$ para su posterior visualización.

Visualización de ADN en geles de agarosa Las muestras de ADN fueron analizadas en geles de agarosa al $1 \%$ teñidos con bromuro de etidio y aplicando 70 Voltios durante 45 minutos. El ADN en el gel fue visualizado empleando un fotodocumentador Bio-Rad ${ }^{\circledR}$ con el software Quantity-One ${ }^{\circledR}$.

\section{Detección de begomovirus mediante PCR}

Se realizó reacción en cadena de la polimerasa empleando oligos degenerados para la detección específica del género begomovirus grupo bipartita, que permiten la amplificación de fragmentos de $1.1 \mathrm{~kb}$ del componente genómico A (Rojas, 1993). También se emplearon los oligos MP16 y MP18, los cuales amplifican una región entre $0,4-0,5 \mathrm{~kb}$ del componente genómico A de los begomovirus (Umaharan, Padidam, Phelps, Beachy y Fauquet, 1998). Las condiciones utilizadas de PCR fueron las reportadas por cada uno de los autores de éstos oligos. Como control positivo se utilizó un plásmido que porta el PYMV previamente clonado por nuestro grupo. Los fragmentos amplificados fueron teñidos con bromuro de Etidio y después visualizados en un gel de agarosa al $1 \%$. 


\section{RESULTADOS Y DISCUSIÓN}

\section{Recolección de arvenses \\ e identificación taxonómica}

Se colectaron 36 arvenses, distribuidas así: 23 en las fincas San Luis y vereda Buenas tardes en Pasca; y 13 en la finca Brisas de Xochimilco, ubicadas en Fusagasugá, Cundinamarca. Adicionalmente, se colectaron 6 muestras de tomate (Solanum lycopersicum) con síntomas virales; esto con el fin de determinar la presencia de begomovirus en estas muestras y así hacer la correlación de los resultados con lo encontrado en las arvenses. De las arvenses colectadas, 22 fueron identificadas taxonómicamente, quedando pendiente de identificar 14 de ellas (Tabla 1).

Tabla 1. Identificación taxonómica de arvenses colectadas en cultivos de tomate localizados en los municipios de Pasca y Fusagasugá, Cundinamarca

\begin{tabular}{|c|c|c|c|c|}
\hline Clave & Localidad & Nombre Vulgar & Nombre Científico & Observaciones \\
\hline PS1 & \multirow{22}{*}{ Pasca } & Trébol & Oxalis latifolia & Presencia de mosca blanca. \\
\hline PS4 & & Papunga & Bidens pilosa & Presencia de mosca blanca \\
\hline PS6 & & Mostacilla & Brassica campestris & Asintomática \\
\hline PS7 & & Pepino de monte & Melothria sp. & Presencia de mosca blanca \\
\hline PS8 & & PD* & PD* & Presencia de mosca blanca \\
\hline PS9 & & Lengua de vaca & Rumex cf. crispus & Presencia de mosca blanca \\
\hline PS10 & & PD* & PD* & Presencia de mosca blanca \\
\hline PS11 & & PD* & PD* & Presencia de mosca blanca \\
\hline PS12 & & PD* & PD* & Presencia de mosca blanca \\
\hline PS13 & & Batatilla & Ipomoea sp. & Presencia de mosca blanca \\
\hline PS14 & & PD* & Asteraceae & Asintomática \\
\hline PS15 & & Mataganado & Persicaria nepalensis & Presencia de mosca blanca \\
\hline PS16 & & PD* & PD* & Presencia de mosca blanca \\
\hline PS18 & & Pamplina & Stellaria media & Presencia de mosca blanca \\
\hline PS19 & & Chachalagua & Veronica persica & Presencia de mosca blanca \\
\hline PS20 & & PD* & Rubus sp. & Asintomática \\
\hline PS21 & & Batatilla & Ipomoea sp. & Asintomática \\
\hline PS22 & & Batatilla & Ipomoea sp. & Asintomática \\
\hline PS24 & & PD* & Rytidostylis sp. & Asintomática \\
\hline PS25 & & Botonera & Malva sylvestris & Asintomática \\
\hline PS26 & & PD* & PD* & Asintomática \\
\hline PS27 & & Escoba & Sida rhombifolia & Asintomática \\
\hline
\end{tabular}


Continuación tabla 1

\begin{tabular}{|c|c|c|c|c|}
\hline Clave & Localidad & Nombre Vulgar & Nombre Científico & Observaciones \\
\hline FS28 & \multirow{14}{*}{ Fusagasugá } & PD* & PD* & Asintomática \\
\hline FS29 & & PD* & PD* & Presencia de mosca blanca \\
\hline FS31 & & Botón negro & Hyptis capitata & Asintomática \\
\hline FS32 & & Chiba & Ageratum conyzoides & Asintomática \\
\hline FS34 & & Yuyo - Guasca & Galinsoga ciliata & Asintomática \\
\hline FS35 & & PD* & PD* & Presencia de mosca blanca \\
\hline FS36 & & Botón negro & Hyptis capitata & Asintomática \\
\hline FS37 & & Bledo & Amaranthus sp. & Asintomática \\
\hline FS38 & & Melón de monte & Melonthria sp. & Asintomática \\
\hline FS39 & & PD* & PD* & Asintomática \\
\hline FS40 & & PD* & PD* & Presencia de mosca blanca \\
\hline FS41 & & $\mathrm{PD} *$ & PD* & Asintomática \\
\hline FS42 & & PD* & PD* & Asintomática \\
\hline FS43 & & PD* & PD* & Asintomática \\
\hline
\end{tabular}

*PD, Por determinar.

\section{Detección de begomovirus mediante Reacción en Cadena de la Polimerasa (PCR)}

Se realizó la extracción de ADN genómico total de todas las arvenses colectadas. Se obtuvo un ADN de buena calidad y concentración en casi todas las muestras evaluadas. Con la excepción de algunas muestras que presentaron dificultades en su molienda y/o extracción debido a su alto contenido de compuestos fenólicos así como de carbohidratos. Adicionalmente con el fin de verificar la calidad de los ADN purificados, se llevó a cabo una amplificación del gen ribosomal 18S (datos no mostrados).

La detección viral por PCR con oligos degenerados específicos para begomovirus bipartitas dio positivo para 5 arvenses: Stellaria media (L.) Vill. (PS18), Veronica pérsica Poir. (PS19), Malva sylvestris L. (PS25) y una planta de la familia Asteraceae (PS14) en las que se evidenció la amplificación del fragmento de $1.1 \mathrm{~kb}$ correspondiente al componente genómico A begomoviral (Figura 1). 


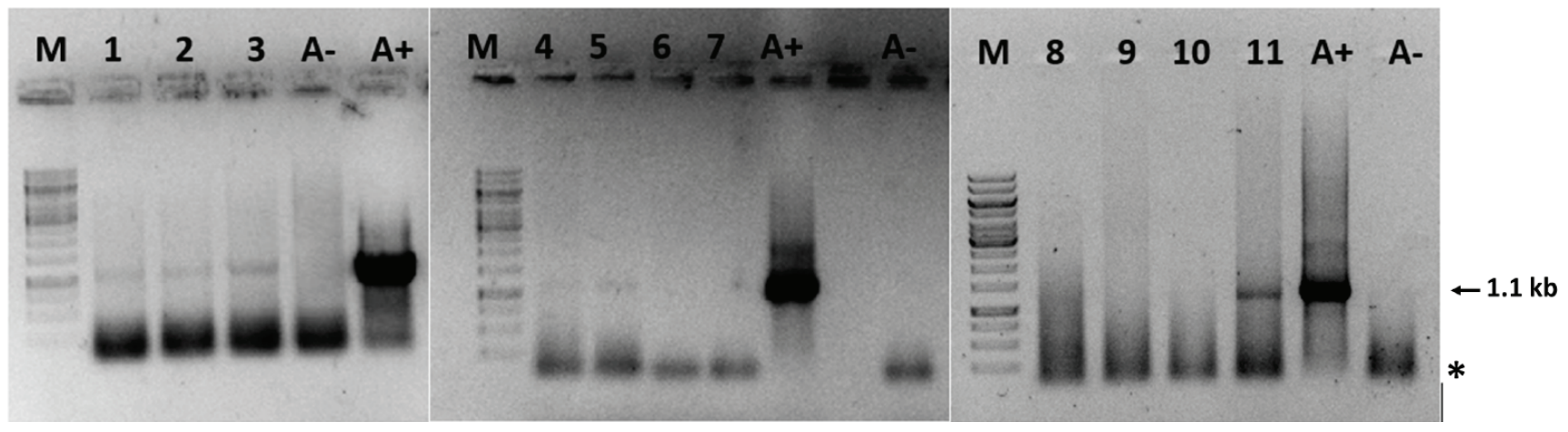

Figura 1. Detección de begomovirus en arvenses colectados en la finca San Luis y la vereda Buenas tardes en Pasca, Cundinamarca, en cultivos de tomate. PCR para el componente A que amplifica un fragmento de $1,1 \mathrm{~kb}$ correspondiente al componente genómico A begomoviral usando los primers PAL1v1978 / PARc496. M, Marcador de peso molecular Gene ruler 1kb ADN Ladder Fermentas; 1, PS18_Stellaria media; 2, PS18_SteIlaria media; 3, PS19_Veronica pérsica; A-, Control negativo; A+, Control positivo. 4, PS14_Asteraceae; 5, PS17_Solanum lycopersicum; 6, PS18_Stellaria media; 7, PS19_Veronica pérsica; A+, Control positivo de A; A-, Control negativo de A. 8, PS21_Ipomoea sp.; 9, PS22_Ipomoea sp.; 10, PS23_Solanum lycopersicum; 11, PS25_Malva sylvestris; A+, Control positivo de A; A-, Control negativo de A. La flecha indica la banda esperada de $1,1 \mathrm{~kb}$. El asterisco $(*)$ indica exceso de primer.

En la Figura 2 se observa la detección de begomovirus en la arvense Galinsoga ciliata (Raf.) S.F. Blake (FS34) empleando los primers MP16 y MP82, que amplifican un fragmento de $0.5 \mathrm{~kb}$ correspondiente a la región $5^{\prime}$ del gen que codifica para la proteína de la cápside $(\mathrm{CP})$ del componente genómico $A$.
Adicionalmente muestras de tomate colectadas en los lotes de Pasca (Figura 1, muestra 5) y Fusagasugá (Figura 2, muestra 33) resultaron positivos para begomovirus, indicando la presencia de este virus en los cultivos donde se colectaron las arvenses positivas.

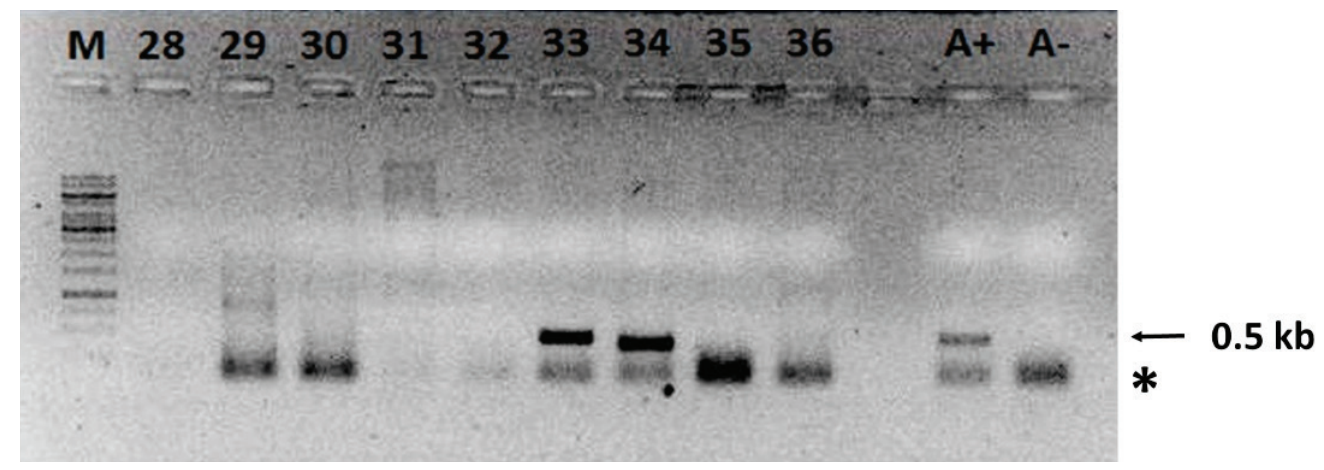

Figura 2. Detección de begomovirus bipartitas en arvenses colectados en la finca Brisas de Xochimilco, Fusagasugá, Cundinamarca, en cultivos de tomate. PCR para el componente A amplifica un fragmento de 0,5 kb. M, Marcador de peso molecular Gene ruler 1kb ADN Ladder Fermentas: 28, FS28_Arvense no identificada; 29, FS29_Arvense no identificada; 30, FS30_Cucurbita sp; 31, FS31_Hyptis capitata; 32, FS32_Ageratum conyzoides; 33, SF33_Solanum lycopersicum; 34, FS34_Galinsoga ciliata; 35, FS35_Arvense no identificada; 36, FS36_Hyptis capitata; A+, control positivo; A-, control negativo. La flecha indica la banda esperada de $~ 0,4-$ $0,5 \mathrm{~kb}$. El asterisco $(*)$ indica exceso de primer. 


\section{Arvenses identificadas como reservorio de begomovirus bipartitos en cultivos de tomate de Cundinamarca.}

Con base en los resultados obtenidos mediante la técnica de reacción en cadena de la polimerasa, se determinó que las arvenses SteIlaria media (L.) Vill., Veronica persica Poir., que tenían presencia de mosca blanca, Malva sylvestris L., Galinsoga ciliata (Raf.) S.F. Blake, y la especie perteneciente a la familia Asteraceae, que fenotípicamente eran asintomáticas y que fueron colectadas en cultivos de tomate en Cundinamarca, eran hospederos alternos de begomovirus (Figura 3).

Para el género Stellaria, solo existe un reporte realizado por Kil et al. (2015), quienes encontraron que la especie Stellaria aquatica (L.) Scop. resultó ser reservorio del virus del rizado amarillo de la hoja del tomate (Tomato YeIlow Leaf Curl Virus - TYLCV), un begomovirus que afecta severamente los cultivos de tomate no solo en Corea del Sur sino alrededor del mundo. A la fecha TYLCV no ha sido detectado afectando esta solanácea en Colombia. En el caso de la arvense Stellaria media (L.) Vill. este es el primer reporte a nivel mundial como reservorio potencial de begomovirus.

Aunque la especie Veronica persica Poir. se ha reportado como hospedero alterno de TYLCV en Corea del sur (Kil et al. 2014), este estudio constituiría el primer reporte de esta especie como reservorio de begomovirus en América.

En cuanto se refiere a la arvense perteneciente a la familia Asteraceae, los resultados de este estudio permiten identificar por vez primera esta planta como reservorio de begomovirus en Colombia. Arnaud, Santos, Lima y Feitosa (2007), reportaron a las especies Bidens pilosa L. y Ageratum conyzoides L. pertenecientes a la familia Asteraceae como reservorio natural de begomovirus en la región de Ibiapaba en
Brasil; este resultado es interesante ya que, en la presente investigación, la especie Bidens pilosa L. no resulto positiva como hospedero alterno de begomovirus.

A nivel mundial se ha reportado diferentes especies del género Galinsoga como hospederos alternos de diversos virus, como, por ejemplo: el virus de la marchitez manchada del tomate (tomato spotted wilt virus - TSWV) del género Tospovirus (Cho, 1986; Stobbs, Broadbent, Allen, \& Stirling, 1992; Verhoeven \& Roenhorst, 1994), el virus del mosaico del pepino (cucumber mosaic virus - CMV) y el virus del mosaico de Galinsoga (Galinsoga mosaic virus - GMV) (Batra, 1979; Behncken, 1970). También se ha reportado que especies del género Galinsoga son susceptibles al virus de la mancha necrótica del impatiens (impatiens necrotic spot virus - INSV), un virus del género Orthotospovirus (Okuda, Fuji, Okuda, Sako, \& Iwanami, 2010). Específicamente la especie Galinsoga parviflora Cav. se ha reportado como hosperdera de begomovirus como: el virus del rizado de la hoja amarilla del chile (pepper yellow leaf curl virus - PepYLCV) (Meliansyah, Hendrastuti, y Hamzah, 2011); el virus India de la hoja rizada del tomate (India tomato leaf curl virus - IToLCV) y el virus de la hoja rizada del tomate (tomato leaf curl virus - ToLCV) Marchoux, Gognalons, y Gébré, 2008). Para el caso de la especie Galinsoga ciliata (Raf.) S.F. Blake. evaluada en este estudio, se encontró la presencia de begomovirus por PCR. Hasta el momento a nivel mundial no existe ningún registro de la especie G. ciliata como hospedera de begomovirus, por lo que se puede afirmar con base en los resultados del presente estudio que este es el primer reporte de esta arvense como hospedero alterno de este género viral.

Nuestro estudio detectó en la arvense Malva sylvestris L. la presencia de begomovirus, 
siendo este el primer reporte de un begomovirus en esta especie en Colombia. Esta maleza ya ha sido reportada como hospedero alterno de begomovirus en otras latitudes del planeta, como lo demuestran los trabajos de Jordá et al. (2000) quienes en muestras de M. sylvestris L. encontraron presencia de begomovirus tales como el virus Nueva Dehli del rizado de la hoja del tomate (tomato leaf curl New Dehli virus - ToLCNDV), así como el TYLCV en Syria. Además de ser también hospedero de virus de pertenecientes a otros géneros virales tales como el TSWV y CMV presentes en arvenses colectadas en el noreste de España (Jordá et al., 2000; Laviña, Aramburu, \& Moriones, 1996).

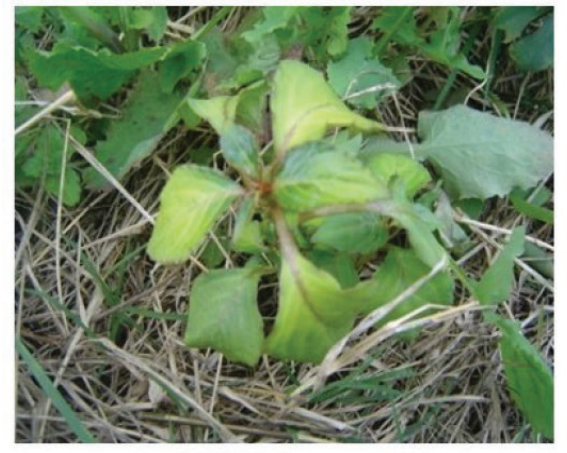

PS14. Asteraceae



PS18. Stellaria media (L.) Vill.

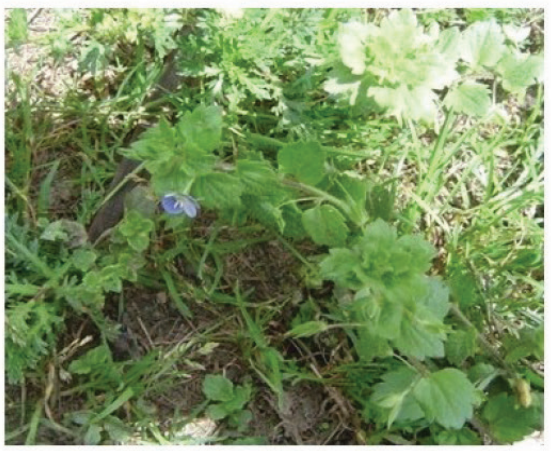

PS19. Veronica persica Poir.

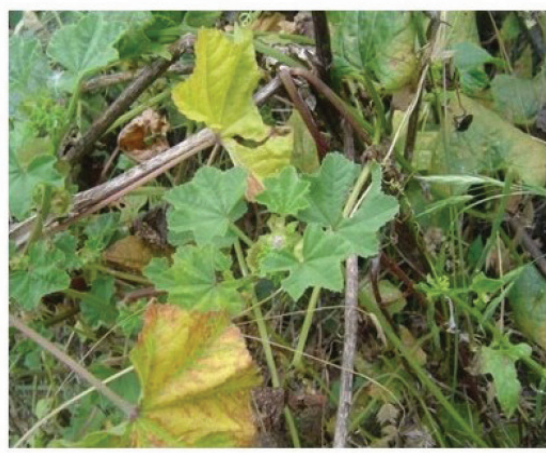

PS25. Malva sylvestris $L$.

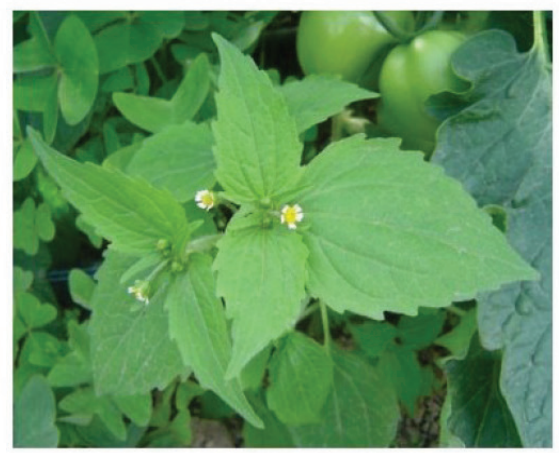

FS34. Galinsoga ciliata (Raf.) S.F. Blake.

Figura 3. Arvenses hospederas de begomovirus bipartitas colectados en la finca San Luis (PS14, PS18 y PS19), vereda Buenas tardes (PS25) y en Brisas de Xochimilco (FS34) ubicadas en Pasca y Fusagasuga, Cundinamarca, en cultivos de tomate.

\section{CONCLUSIONES}

Este estudio encontró que las arvenses SteIlaria media (L.) Vill., Veronica persica Poir y una especie de la familia Asteracea, recolectadas en la finca San Luis; la arvense Malva sylvestris L., recolectada en la vereda Buenas tardes, en el municipio de Pasca; y la arvense Galinsoga ciliata (Raf.) S.F. Blake recolectada en la finca Brisas de Xochimilco en el municipio de Fusagasugá son nuevos hospederos del begomovirus. Por primera vez a nivel mundial, se reportan como hospederos de begomovirus a las especies SteIlaria media (L.) Vill. y Galinsoga ciliata. Se reporta por primera vez para el continente americano la especie Veronica persica Poir como hospedero de begomovirus; mientras que la especie Malva sylvestris L. y una especie de la familia Asteraceae se reportan por primera vez en Colombia como reservorios de begomovirus. 
El control de las arvenses identificadas como hospederos alternativos para begomovirus, es una estrategia que podría disminuir el impacto de estos virus en los cultivos de tomate.

\section{LITERATURA CITADA}

Arnaud, L., Santos, C., Lima, J., Feitosa, F. (2007). Predominância de Begomovírus em Tomateiros na Região Produtora da Ibiapaba, Ceará e sua Deteç̧ão Natural em Plantas Daninhas. Fitopatologia Brasileira 32:241-246.

Batra, S. W. T. (1979). Insects Associated with Weeds of the Northeastern United States: Quickweeds, Galinsoga ciliata and G. parviflora (Compositae) 1. Environmental Entomology, 8(6), 1078-1082. https://doi.org/10.1093/ee/8.6.1078

Behncken, G. (1970). Some properties of a virus from Galinsoga parviflora. Australian Journal of Biological Sciences, 8(Behncken 1968), 497-501.

Cho, J. J. (1986). Reservoir Weed Hosts of Tomato Spotted Wilt Virus. Plant Disease, 70(11), 1014. https://doi.org/10.1094/PD-70-1014

Duffus, J. E. (1971). Role of Weeds in the Incidence of Virus Diseases. Annual Review of Phytopathology, 9(1), 319-340. https://doi.org/10.1146/annurev.py.09.090171.001535

Fargette, D., Konaté, G., Fauquet, C., Muller, E., Peterschmitt, M., Thresh, J.M. (2006). Molecular Ecology and Emergence of Tropical Plant Viruses. Annual review of phytopathology. 44. 235-60. 10.1146/annurev. phyto.44.120705.104644.

Jones, R. A. C. (2014). Trends in plant virus epidemiology: opportunities from new or improved technologies. Virus Research, 186, 3-19. https:// doi.org/10.1016/j.virusres.2013.11.003

Jordá, C., Font, I., Lázaro, A., Juarez, M., Ortega, A., \& Lacasa, A. (2000). New Natural Hosts of Tomato spotted wilt virus. Plant Disease, 84(4), 489-489. https://doi.org/10.1094/ PDIS. 2000.84.4.489D

Kil, E., Byun, H., Kim, S., Cho, S., Cho, S., Roh, K., Lee, K., Choi, H., Kim, C., Lee, S. (2015). Tomato Yellow leaf curl virus can overwinter in Stellaria aquatica a winter-hardy TYLCV-reservoir weed. Plant Disease, 99(5):588-592. doi: 10.1094/ PDIS-04-14-0352-RE

Kil, E., Park, J., Lee, H., Kim, J., Choi, H., Lee, K., Kim, C., Lee, S. (2014). Lamium amplexicaule
(Lamiaceae): a weed reservoir for tomato yellow leaf curl virus (TYLCV) in Korea. Archives of Virology, 159:1305-1311.

Laviña, A., Aramburu, J., \& Moriones, E. (1996). Occurrence of tomato spotted wilt and cucumber mosaic viruses in field-grown tomato crops and associated weeds in northeastern Spain. Plant Pathology, 45(5), 837-842. https://doi. org/10.1111/j.1365-3059.1996.tb02893.x

Lopez-lopez, K., Jara-Tejada, F., \& Vaca-Vaca, J. C. (2014). Nuevos hospederos alternativos de Begomovirus identificados en el Valle del Cauca. Fitopatología Colombiana, 38: 19-23.

Marchoux, G., Gognalons, P., \& Gébré Sélassié, K. (2008). Virus des Solanacées : du génome viral à la protection des cultures. Éd. Quae.

Meliansyah, R., Hendrastuti Hidayat, S., \& Hamzah Mutaqin, K. (2011). Geminiviruses Associated with the Weed Species Ageratum conyzoides, Centipeda minima, Porophyllum ruderale, and Spilanthes iabadicensis from Java, Indonesia. Microbiology Indonesia, 5(2), 120-124. https:// doi.org/10.5454/mi.5.3.4

Meza, J., Pantoja, A., Galan, P. R., Godoy, N., Gattini, J., Villasanti, C., Díaz, J. (2013). El Cultivo De Tomate Con Buenas Prácticas Agrícolas En La Agricultura Urbana Y Periurbana. FAO. E-ISBN 978-92-5-307780-9

Okuda, M., Fuji, S., Okuda, S., Sako, K., \& Iwanami, T. (2010). Evaluation of the potential of thirtytwo weed species as infection sources of Impatiens necrotic spot virus. Journal of Plant Pathology, 92(2), 357-361.

Prajapat, R., Marwal, A., \& Gaur, R. K. (2014). Begomovirus associated with alternative host weeds: a critical appraisal. Archives of Phytopathology and Plant Protection, 47(2), 157-170. https://doi. org/10.1080/03235408.2013.805497

Rojas, M. R. (1993). Use of Degenerate Primers in the Polymerase Chain Reaction to Detect Whitefly-Transmitted Geminiviruses. Plant Disease. https://doi.org/10.1094/PD-77-0340

Stobbs, L. W., Broadbent, A. B., Allen, W. R., \& Stirling, A. L. (1992). Transmission of tomato spotted wilt virus by the western flower thrips to weeds and native plants found in southern Ontario. Plant Disease (USA), 76, 23-29. Recuperado de http://agris.fao.org/agris-search/search. do? recordID = US9439290 
Tamayo M., P. J., \& Jaramillo, J. E. (2013). Enfermedades del tomate, pimentón, ají y berenjena en Colombia : guía para su diagnóstico y manejo. Corpoica. Recuperado de http://biblioteca.humboldt.org.co/cgi-bin/koha/opac-detail. pl?biblionumber $=8433$

Thompson, W. (2011). The Whitefly, Bemisia tabaci (Homoptera: Aleyrodidae) Interaction with Geminivirus-Infected Host Plants. 10.1007/97894-007-1524-0.

Umaharan, P., Padidam, M., Phelps, R. H., Beachy, R. N., \& Fauquet, C. M. (1998). Distribution and Diversity of Geminiviruses in Trinidad and Tobago. Phytopathology, 88(12), 1262-1268. https:// doi.org/10.1094/PHYTO.1998.88.12.1262

Vaca-Vaca, J. C., Betancur-Pérez, J. F., \& LópezLópez, K. (2012). Distribución y diversidad genética de Begomovirus que infectan tomate (Solanum lycopersicum L) en Colombia. Revista Colombiana de Biotecnología, 14(1), 60-76. Recuperado de http://www.scielo.org. co/scielo.php?script $=$ sci_arttext\&pid $=$ S012334752012000100007\& $\mathrm{nrm}=$ iso

Vaca-Vaca, J. C., Carrasco-Lozano, E. C., \& LópezLópez, K. (2018). Molecular identification of a new begomovirus infecting yellow passion fruit (Passiflora edulis) in Colombia. Archives of Virology, 162(2), 573-576. https://doi.org/10.1007/ s00705-016-3098-y

Vaca-Vaca, J. C., Corredor-Saenz, V. C., Jara-Tejada, F., Betancourt-Andrade, D., \& Lopez-Lopez, K. (2019). Nuevos hospederos alternativos de Begomovirus asociados con el cultivo de ají en el Valle del Cauca, Colombia. Acta Agronómica,
68(1), 56-60. https://dx.doi.org/10.15446/acag. v68n1.77487

Vaca-Vaca, J. C., Otavo-Fiscal, D., \& López-López, K. (2011). Identificación de arvenses como hospederos naturales de Begomovirus en el Valle del Cauca, Colombia. Fitopatología Colombiana, 35(2), 69-72.

Verhoeven, J. T. J., \& Roenhorst, J. W. (1994). Tomato spotted wilt virus: Ecological aspects in ornamental crops in the Netherlands from 1989 up to 1991. Acta Horticulturae, (377), 175-182. https://doi.org/10.17660/ActaHortic.1994.377.18

Zerbini $F$, Briddon $R$, Idris $A$, Martin $D$, Moriones E, Navas-Castillo J, Rivera-Bustamante R, Roumagnac P, Varsani A, ICTV Report Consortium (2017). ICTV Virus Taxonomy Profile: Geminiviridae. J. Gen. Virol. 98(2):131-133 doi:10.1099/ jgv. 0.000738

\section{AGRADECIMIENTOS}

Al Departamento Administrativo de Ciencia, Tecnología e Innovación (COLCIENCIAS), por el apoyo financiero de la presente propuesta para desarrollar un semillero de investigación.

D. M. Rivera-Toro y J. Morales-Euse agradecen a la Dirección de Investigación y Extensión de la Universidad Nacional de Colombia sede Palmira por el apoyo financiero recibido a través de los proyectos código Hermes 27071 y 32316, respectivamente. 
